Catalyst Papers in Press are peer-reviewed, accepted articles that have not yet been edited or formatted, but may be cited by DOI. The final version may contain substantive or nonsubstantive changes.

doi: 10.5344/catalyst.2021.21003

\section{ASEV CATALYST REPORT}

\title{
Analysis of Free Hydrogen Sulfide in Wines Using Gas Detection Tubes
}

\author{
Rachel B. Allison, ${ }^{1}$ Austin Montgomery, ${ }^{1}$ and Gavin L. Sacks ${ }^{1 *}$ \\ ${ }^{1}$ Department of Food Science, Cornell University, 411 Tower Road, Ithaca, NY 14853. \\ *Corresponding author (gls9@cornell.edu; 1-607-255-2335) \\ Acknowledgments: The authors thank the Natural Science and Engineering Research Council of \\ Canada for providing a doctoral research scholarship to R.B.A. Financial support from the \\ Saltonstall Wine Endowment and the New York Wine and Grape Foundation are also gratefully \\ acknowledged. All contributing authors have approved the manuscript submission and that the \\ manuscript is not currently under review with another publication.
}

Manuscript submitted April 16, 2021, revised July 8, 2021, accepted July 12, 2021

This is an open access article distributed under the CC BY license (https://creativecommons.org/ licenses/by/4.0/).

By downloading and/or receiving this article, you agree to the Disclaimer of Warranties and Liability. The full statement of the Disclaimers is available at https://www.asevcatalyst.org/content/proprietary-rights-notice-catalyst. If you do not agree to the Disclaimers, do not download and/or accept this article.

\section{Summary}

Goals: Hydrogen sulfide $\left(\mathrm{H}_{2} \mathrm{~S}\right.$, "rotten egg" aroma) concerns winemakers due to its contribution to sulfur-like off-aromas (SLOs). However, there are a lack of inexpensive, convenient methods for quantitation of $\mathrm{H}_{2} \mathrm{~S}$ in wines at or below its reported odor threshold. The use of selective, colorimetric gas detection tubes (GDT) for measurement of $\mathrm{H}_{2} \mathrm{~S}$ during fermentation has been previously described, but this approach has not been adapted and validated for finished wines. We developed and validated protocols for rapid, inexpensive analysis of $\mathrm{H}_{2} \mathrm{~S}$ using GDTs and 
Catalyst Papers in Press are peer-reviewed, accepted articles that have not yet been edited or formatted, but may be cited by DOI. The final version may contain substantive or nonsubstantive changes.

doi: $10.5344 /$ catalyst.2021.21003

Aeration-Oxidation (A-O) glassware commonly available in wineries. Video demonstration of the approaches is also provided (Supplemental Video 1).

\section{Key Findings:}

- Two approaches were validated for GDT-based quantitation of $\mathrm{H}_{2} \mathrm{~S}$ in wine. In the first approach, $\mathrm{H}_{2} \mathrm{~S}$ was sparged from the sample with $\mathrm{N}_{2}$ gas, analogous to Monier-Williams analyses of $\mathrm{SO}_{2}$. In the second approach, $\mathrm{H}_{2} \mathrm{~S}$ was sparged by a vacuum-generated air stream, analogous to A-O analyses of $\mathrm{SO}_{2}$.

- Both approaches require $<15 \mathrm{~min} /$ sample and achieve excellent linearity. The calibration curve for the $\mathrm{N}_{2}$ Method was identical to the curve predicted from the manufacturer's markings. The Aspiration Method was less sensitive, likely because of oxidative losses. However, the Aspiration Method was simpler to set up, operate, and adapt to higher concentration samples.

- The limits of detection were $12-13 \mathrm{ng} \mathrm{H}_{2} \mathrm{~S}$ for the methods, or $\sim 0.2 \mu \mathrm{g} / \mathrm{L}$ using a $60 \mathrm{~mL}$ sample. The mean coefficients of variance $(\% \mathrm{CV})$ were $<5 \%$ for both approaches.

- Using the new method, we observed that commercially purchased wines stored in aluminum cans have significantly higher $\mathrm{H}_{2} \mathrm{~S}$ than commercial wines in glass packaging.

Significance: The novel methods can be used for routine $\mathrm{H}_{2} \mathrm{~S}$ analysis in wineries without the need for significant investment in new equipment. In addition to cost savings, the ability to test $\mathrm{H}_{2} \mathrm{~S}$ onsite rather than send samples to an external lab decreases the risk of $\mathrm{H}_{2} \mathrm{~S}$ losses through oxidation or volatilization. These new analytical tools can be used for benchmarking, diagnosing 
Catalyst Papers in Press are peer-reviewed, accepted articles that have not yet been edited or formatted, but may be cited by DOI. The final version may contain substantive or nonsubstantive changes.

doi: 10.5344/catalyst.2021.21003

47 faulty wines, or evaluating the effects of winemaking parameters, such as yeast selection,

48 remediation treatments, and packaging options on $\mathrm{H}_{2} \mathrm{~S}$.

Keywords: gas detection tubes, reduced aromas, sulfide analysis, wine fault

\section{Overview}

51 Sulfur-like off-aromas (SLOs) are one of the most common faults observed in commercial

52 wines ${ }^{1}$. Although several sulfhydryls can contribute to SLOs, hydrogen sulfide $\left(\mathrm{H}_{2} \mathrm{~S}\right)$ is reported

53 to be the $S$-compound most frequently in excess of its sensory threshold $(\sim 1 \mu \mathrm{g} / \mathrm{L})^{1}$ in wines with

54 this fault. $\mathrm{H}_{2} \mathrm{~S}$ may contribute directly to SLOs due to its rotten egg aroma and/or its presence

55 could serve as a marker for other related malodorous sulfhydryls. $\mathrm{H}_{2} \mathrm{~S}$ can be produced during

56 fermentation through several pathways, including as an intermediary step in $S$-amino acid

57 biosynthesis; ${ }^{2}$ as a degradation product of $\mathrm{S}^{0}$ fungicide residues; $;{ }^{3,4}$ and through catabolism of $S$ -

58 amino acids, especially cysteine ${ }^{5} . \mathrm{H}_{2} \mathrm{~S}$ formed during fermentation will be partially lost due to

$59 \mathrm{CO}_{2}$ entrainment ${ }^{6}$ and can be further diminished post-fermentation by winemaking approaches

like copper addition or aeration ${ }^{7}$. However, these approaches can generate precursor compounds

61 (copper sulfide complexes; organopolysulfanes) capable of releasing $\mathrm{H}_{2} \mathrm{~S}$ during the reductive

62 storage conditions typical of bottled wine, i.e. low oxygen in the presence of $\mathrm{SO}_{2}{ }^{8-10}$. Finally, $\mathrm{H}_{2} \mathrm{~S}$ is anecdotally reported to form through storage of wine in aluminum cans, possibly due to

64 reaction of $\mathrm{SO}_{2}$ with the aluminum metal as well as the previously described precursors. Thus, enologists may wish to quantify $\mathrm{H}_{2} \mathrm{~S}$ not only to determine its potential contribution to faulty wines, but also to evaluate winemaking parameters such as yeast selection, fermentation conditions, remediation treatments, and packaging options. 
Catalyst Papers in Press are peer-reviewed, accepted articles that have not yet been edited or formatted, but may be cited by DOI. The final version may contain substantive or nonsubstantive changes.

doi: 10.5344/catalyst.2021.21003

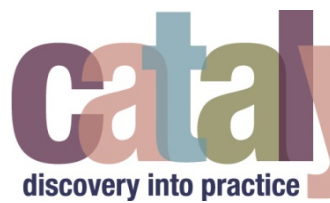

$\mathrm{H}_{2} \mathrm{~S}$ is reported to be in the range of 1-20 $\mu \mathrm{g} / \mathrm{L}$ in wines at the end of fermentation ${ }^{11}$, and its low concentration and high reactivity requires the use of specialized analytical approaches. Early reports on $\mathrm{H}_{2} \mathrm{~S}$ quantification in wines generally relied on laborious wet-chemical approaches, e.g. capturing sparged $\mathrm{H}_{2} \mathrm{~S}$ with a $\mathrm{Cd}(\mathrm{OH})_{2}$ solution, followed by redox titration with methylene blue $^{12}$. More recent reports utilize gas chromatography (GC) coupled with a range of detectors, including pulsed-flame photometric detection (PFPD) ${ }^{13}$ and sulfur chemiluminescence detection $(\mathrm{SCD})^{1}$. These methods offer excellent detection limits $(<1 \mu \mathrm{g} / \mathrm{L})$ and high selectivity but are inappropriate for use in most commercial wineries due to the expense of the equipment and specialized skill necessary for their operation. Additionally, $\mathrm{H}_{2} \mathrm{~S}$ is highly volatile and readily oxidized, which necessitates considerable precautions during sample handling.

A modern version of classic colorimetric approaches utilizes gas detection tubes (GDT) for elective $\mathrm{H}_{2} \mathrm{~S}$ quantification. Originally developed for the mining industries, GDTs for $\mathrm{H}_{2} \mathrm{~S}$ are composed of glass tubes filled with an inert packing coated with an appropriate indicator compound, e.g., lead acetate. As $\mathrm{H}_{2} \mathrm{~S}$ flows through the tube, it reacts irreversibly and causes a discoloration such that the length of the stain is proportional to the mass of $\mathrm{H}_{2} \mathrm{~S}$ passing through the tube. An example of discoloration in different GDTs is provided in the Supplemental Information

The use of GDTs for measurement of $\mathrm{H}_{2} \mathrm{~S}$ in enological studies was first reported for measurement of total $\mathrm{H}_{2} \mathrm{~S}$ produced by yeast strains during small-scale fermentations ${ }^{14,15}$. These reports use the $\mathrm{CO}_{2}$ produced during fermentation to force $\mathrm{H}_{2} \mathrm{~S}$ through the GDT, an approach that is not viable for post-fermentation wines without $\mathrm{CO}_{2}$. For post-fermentation $\mathrm{H}_{2} \mathrm{~S}$ analysis, 
Catalyst Papers in Press are peer-reviewed, accepted articles that have not yet been edited or formatted, but may be cited by DOI. The final version may contain substantive or nonsubstantive changes.

doi: $10.5344 /$ catalyst.2021.21003

our group previously reported that $\mathrm{CO}_{2}$ could be generated in situ through addition of carbonatecontaining antacid tablets to a flask containing a wine sample and fitted with a GDT. However, this approach results in a shift of the $\mathrm{pH}$ to $\sim 6$, which could potentially release $\mathrm{H}_{2} \mathrm{~S}$ from known precursors ${ }^{16}$. Additionally, the rapid generation of $\mathrm{CO}_{2}$ gas can occasionally result in dislodging the detection tube or another connection.

In this work, we describe a rapid, inexpensive method for detecting and quantifying $\mathrm{H}_{2} \mathrm{~S}$ in still wine samples using a GDT and the widely available Aeration-Oxidation (A-O) apparatus. We report figures of merit, apply the assay to commercial wines, and provide a detailed video description of the protocol (Supplemental Video 1).

\section{Major Observations and Interpretations}

Apparatus and materials. The principle for the proposed $\mathrm{H}_{2} \mathrm{~S}$ method is based on the GDT protocols previously developed for measurement of $\mathrm{S}^{0}$ residues in grape must ${ }^{3}$ or $\mathrm{H}_{2} \mathrm{~S}$ formed following release from wine precursors or during the course of fermentation ${ }^{14,17}$. The current approach used either inert gas ( $\mathrm{N}_{2}$ Method) or vacuum aspiration (Aspiration Method) to sparge $\mathrm{H}_{2} \mathrm{~S}$ from the sample and through the GDT tube (Figs 1a and 1b), resulting in a discoloration of the tube (Supplementary Figure A). The flask and tubes are connected in series through PVC tubing. A sufficient length of PVC tubing (15 cm or more) between sample flask and the first GDT is recommended to prevent splashing of water droplets and fouling of the GDT inlet. A demonstration of these approaches can be found in the accompanying video (see Supplementary

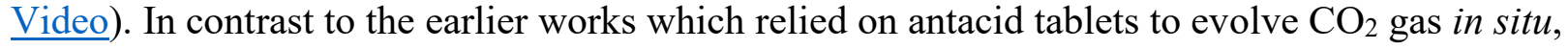
these new approaches did not cause $\mathrm{pH}$ changes or dilution of the sample which could have 
Catalyst Papers in Press are peer-reviewed, accepted articles that have not yet been edited or formatted, but may be cited by DOI. The final version may contain substantive or nonsubstantive changes.

doi: 10.5344/catalyst.2021.21003

risked release of $\mathrm{H}_{2} \mathrm{~S}$ from precursors like copper-sulfhydryl complexes ${ }^{16}$. The antacid-based approaches also required the opening and resealing of the apparatus to sequentially add tablets, which risked losses of $\mathrm{H}_{2} \mathrm{~S}$ due to volatilization.

As described in more detail below, both the $\mathrm{N}_{2}$ and Aspiration Methods yield satisfactory results. However, the Aspiration Method is easier to use in practice, as the $\mathrm{N}_{2}$ Method can overpressure and dislodge the GDT or other components, resulting in leaks. Additionally, the Aspiration Method allows easy replacement of the GDT if the tube becomes saturated during a run. However, the $\mathrm{N}_{2}$ Method produced a calibration curve identical to the curve calculated from the manufacturer's GDT markings, and thus may require less frequent calibration (Fig 2).

\section{GDT selection and interferences from $\mathrm{SO}_{2}$ and other sources: The Gastec 4LL and 4LT}

GDTs are not susceptible to interferences from most wine components, including sulfate, acetic acid, or water vapor ${ }^{3}$. Several other compounds listed by the specification sheets for these GDTs (e.g. ozone, nitrogen dioxide, nitric acid, hydrogen chloride, hydrogen fluoride, ammonia) ${ }^{18}$ are unlikely to be important to wine analyses. However, there are two potentially relevant interferences: thiols (mercaptans) and $\mathrm{SO}_{2}$. Thiols are reported to be an interference for the more sensitive 4LT tubes (which contain $\mathrm{HgCl}_{2}$ ) and not for the 4LL tubes (which contain $\left.\mathrm{Pb}\left(\mathrm{CH}_{3} \mathrm{COO}\right)_{2}\right)$. Although the response of $4 \mathrm{LT}$ tubes to thiols is greater than for $\mathrm{H}_{2} \mathrm{~S}^{14}$, thiols are also less volatile and are typically at lower concentrations in wine ${ }^{1}$. We had previously estimated that interference from methanethiol (the thiol of greatest concern due to volatility and concentration) in a typical wine would be only $25 \%$ of the $\mathrm{H}_{2} \mathrm{~S}$ signal ${ }^{17}$. However, in situations 
Catalyst Papers in Press are peer-reviewed, accepted articles that have not yet been edited or formatted, but may be cited by DOI. The final version may contain substantive or nonsubstantive changes.

doi: $10.5344 /$ catalyst.2021.21003

where interferences from methanethiol or other thiols are of concern, 4LL tubes can substituted at the expense of $\sim 3$-fold lower sensitivity ${ }^{3}$.

$\mathrm{SO}_{2}$ is described as an interference for both $4 \mathrm{LL}$ and $4 \mathrm{LT}$ tubes ${ }^{18}$. Earlier reports by our group using GDTs relied on antacid tablets to generate a gas stream, which buffered the $\mathrm{pH}$ to $\sim 6$ and strongly favored non-volatile forms of $\mathrm{SO}_{2}$ (i.e. bisulfite, sulfite). However, in initial studies at native $\mathrm{pH}$, we observed considerable interferences from model solutions containing $\mathrm{SO}_{2}$ (data not shown). To remove $\mathrm{SO}_{2}$ from the gas stream, we investigated three approaches - addition of $\mathrm{H}_{2} \mathrm{O}_{2}$ or acetaldehyde directly to the sample; using an inline $\mathrm{SO}_{2}$ GDT to scrub the gas stream; and using an inline acetaldehyde solution.

Direct addition of acetaldehyde was not effective at eliminating the interference (data not shown). Addition of $\mathrm{H}_{2} \mathrm{O}_{2}$ to the wine sample was effective at removing the $\mathrm{SO}_{2}$ interference for additions of $0.18 \%$ and $0.35 \%$ by volume but was not pursued further due to concerns about $\mathrm{H}_{2} \mathrm{~S}$ oxidation.

$\mathrm{SO}_{2}$ GDTs were effective in eliminating interferences from $\mathrm{SO}_{2}$. The Gastec $5 \mathrm{Lb}$ and $5 \mathrm{~L} \mathrm{SO}_{2}$ tubes were both tested, and the 5L was ultimately selected for its higher capacity. We also evaluated the use of an inline solution of acetaldehyde (1.5\% v/v; Fig 1(b), Item C). By itself, the inline acetaldehyde solution was unable to fully remove $\mathrm{SO}_{2}$ interferences but including the acetaldehyde trap before the $\mathrm{SO}_{2}$ GDT had the advantage of preserving the lifetime of the $\mathrm{SO}_{2}$ GDT. If this approach is used, then the acetaldehyde solution should be replenished when the $\mathrm{SO}_{2} \mathrm{GDT}$ is replaced. 
Catalyst Papers in Press are peer-reviewed, accepted articles that have not yet been edited or formatted, but may be cited by DOI. The final version may contain substantive or nonsubstantive changes.

doi: $10.5344 /$ catalyst.2021.21003

GDTs respond to the initial mass of $\mathrm{H}_{2} \mathrm{~S}$, and not the initial concentration, and we were able to vary sample volume of model wine or Milli-Q water over a wide range (6 to $66 \mathrm{~mL}$ ) without affecting the relative response (see Supplemental Information, Figure B). We also observed that the stain length stopped increasing after $5 \mathrm{~min}$ for volumes $\leq 10 \mathrm{~mL}$, but at least $10 \mathrm{~min}$ analysis time were necessary for volumes $\geq 60 \mathrm{~mL}$ before tube staining (and thus, $\mathrm{H} 2 \mathrm{~S}$ sparging) was complete. We selected a 10 min analysis time for further experiments, but shorter analysis times of $5 \mathrm{~min}$ may be appropriate for sample volumes of $10 \mathrm{~mL}$ or less.

Calibration and figures of merit for $\mathrm{H}_{2} \mathrm{~S}$ GDTs. Figures of merit for the $\mathrm{N}_{2}$ and Aspiration Methods are summarized in Table 1. We observed a linear relationship $\left(\mathrm{r}^{2}>0.99\right)$ between the length of color change on the $\mathrm{H}_{2} \mathrm{~S}$ GDT and the nominal concentration of the calibration standards for both methods (Fig 2).

\section{(i) $\quad \mathbf{N}_{2}$ Method Length of color change $(\mathrm{mm})=0.100 \times \mathrm{H}_{2} \mathrm{~S}$ (in $\mathrm{ng}$ )}

(ii) Aspiration Method Length of color change (mm) $=0.068 \times \mathrm{H}_{2} \mathrm{~S}$ (in ng)

\section{Theoretical calibration curves based on the manufacturer-provided markings (see Supplementary} Information) were also plotted, along with a curve from a previous report which used antacid tablets as an in situ gas source (Fig 2) ${ }^{17}$. The slope of the theoretical curve based on manufacturers markings (dotted line) was identical to the slope observed for the $\mathrm{N}_{2}$ Method.

However, the slope of the Aspiration Method was about 30\% lower than the theoretical slope, with a similar value reported for the earlier antacid tablet method (dashed line). 
Catalyst Papers in Press are peer-reviewed, accepted articles that have not yet been edited or formatted, but may be cited by DOI. The final version may contain substantive or nonsubstantive changes.

doi: $10.5344 /$ catalyst.2021.21003

The close agreement between the $\mathrm{N}_{2}$ Method slope and the theoretical slope based on manufacturer markings is a potential advantage for this method over the Aspiration Method, as the $\mathrm{N}_{2}$ method could potentially be used with less extensive calibration. The lower sensitivity of the Aspiration Method could be due to partial losses from oxidation of $\mathrm{H}_{2} \mathrm{~S}$ during analyses, as the sample is not protected from air in this analysis. The reason for the lower-than-theoretical sensitivity of the antacid method is less clear, as the evolved $\mathrm{CO}_{2}$ gas should have created an anoxic environment. However, the earlier method required the opening and closing of the reaction flask to add additional tablets, which could have introduced air.

Coefficients of variance $(\% \mathrm{CV})$ were calculated for each of the five calibration standards for each method ( $n=3$ replicates for each standard), and the repeatability calculated as the mean $\% \mathrm{CV}$. We observed excellent repeatability $(\% \mathrm{CV}<5 \%$; Table 1$)$. We also observed excellent within-lab reproducibility (Fig 3). Two standard solutions ( $\mathrm{n}=16$ total) were run at regular intervals over a four-week period without recalibrating the tubes. Data were normalized to the expected value. We observed $95 \%$ confidence interval of $92-97 \%$ recovery (ideal $=100 \%$ ) of the expected signal over the four week experiment.

Based on noise calculations for the lowest calibration standard on the 4LT GDTs, we calculated

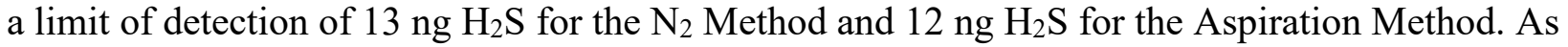
previously reported for GDT methods, the limit of detection is primarily determined by the smallest observable change $(0.5-1.0 \mathrm{~mm})$ in stain length ${ }^{3}$. This can be more challenging for the 4LT tubes than other tubes due to the subtle color change (yellow to pink). Using a $60 \mathrm{~mL}$ sample volume, we could achieve a detection limit of $0.2 \mu \mathrm{g} / \mathrm{L}$. This value is below the reported 
Catalyst Papers in Press are peer-reviewed, accepted articles that have not yet been edited or formatted, but may be cited by DOI. The final version may contain substantive or nonsubstantive changes.

doi: 10.5344/catalyst.2021.21003

odor threshold for $\mathrm{H}_{2} \mathrm{~S}$ in wine ${ }^{1}$ and compares favorably to detection limits reported with more expensive technologies. For example, an LOD of $0.2 \mu \mathrm{g} / \mathrm{L}$ has been reported for $\mathrm{H}_{2} \mathrm{~S}$ using GC$\mathrm{SCD}^{1}$, while quantitation limits of 1.0 and $1.7 \mu \mathrm{g} / \mathrm{L}$ were reported using GC-PFPD ${ }^{13}, 19$.

As mentioned above, 4LT tubes achieve the best sensitivity and detection limits but suffer from interferences from thiols ${ }^{14}$, and the use of the less sensitive Gastec 4LL tube may be prudent when thiol interferences are suspected. Furthermore, the cost of a box of 10 GDTs is $\sim \$ 70$ USD, and tubes cannot be regenerated. Although multiple samples can be analyzed on one GDT until the tube is exhausted, high $\mathrm{H}_{2} \mathrm{~S}$ concentration samples can quickly exhaust the capacity of a Gastec 4LT ( $\sim 500 \mathrm{ng}$ of $\left.\mathrm{H}_{2} \mathrm{~S}\right)$. In practice, we typically used a GDT only once before disposal, particularly when handling samples with unknown $\mathrm{H}_{2} \mathrm{~S}$ concentration when we did not want to risk saturating the GDT. However, reuse of tubes that are not yet saturated was practiced when the expected concentration is known (such as with calibration standards). In general, we recommend using the 4LT tube and $60 \mathrm{~mL}$ sample size for low concentration samples (less than $\sim 5 \mu \mathrm{g} / \mathrm{L})$, and to use a 4LL tube when measuring higher concentration samples or when high levels of thiol interferences are expected.

Analysis of commercial wines. A convenient sample of twelve commercial wines (6 bottled, 6 canned) were purchased from local stores, and were evaluated using the GDT methods (Fig 4). We observed an average $\mathrm{H}_{2} \mathrm{~S}$ concentration in the bottled wines of $1.1 \pm 0.9 \mu \mathrm{g} / \mathrm{L}$, a range consistent with values reported elsewhere ${ }^{1}$. The mean $\mathrm{H}_{2} \mathrm{~S}$ in the canned wines was $13.5 \pm 9.9$ $\mu \mathrm{g} / \mathrm{L}$ significantly higher than the bottled wines $(\mathrm{p}<0.05)$. The highest concentration of $\mathrm{H}_{2} \mathrm{~S}$ in the canned wines was nearly $30 \mu \mathrm{g} / \mathrm{L}$, comparable to the highest values observed in a survey of 
Catalyst Papers in Press are peer-reviewed, accepted articles that have not yet been edited or formatted, but may be cited by DOI. The final version may contain substantive or nonsubstantive changes.

doi: $10.5344 /$ catalyst.2021.21003

211 commercial wines described as "reduced"1. These observations concur with recent anecdotal

212 observations that wines stored in aluminum cans will develop $\mathrm{H}_{2} \mathrm{~S}$ during storage due to i)

213 anoxic conditions and degradation of $\mathrm{H}_{2} \mathrm{~S}$ precursors, and ii) reaction of $\mathrm{SO}_{2}$ with the aluminum

214 metal to form $\mathrm{H}_{2} \mathrm{~S}^{20}$. As a caveat, the effects of packaging may have been confounded with other

215 variables, e.g. production practices used for wines destined for cans, and the higher levels of $\mathrm{H}_{2} \mathrm{~S}$

216 in canned wine are not necessarily due to interactions between the can and wine.

\section{Broader Impact}

We have described and validated two convenient, inexpensive approaches to measuring free $\mathrm{H}_{2} \mathrm{~S}$

219 in commercial wine samples using selective GDTs and glassware from an Aeration-Oxidation operate, making it more practical in winery settings, but should be regularly calibrated with 
Catalyst Papers in Press are peer-reviewed, accepted articles that have not yet been edited or formatted, but may be cited by DOI. The final version may contain substantive or nonsubstantive changes.

doi: 10.5344/catalyst.2021.21003

\section{Experimental Design}

233 Chemical reagents. Ethanol (EtOH) at 140- and 190-proof was from Koptec (King of Prussia, PA). L(+)-tartaric acid (99\%) and hydrogen peroxide $\left(\mathrm{H}_{2} \mathrm{O}_{2}, 35 \% \mathrm{w} / \mathrm{w}\right)$ were purchased from Acros Organics (Morris Plains, NJ). Sodium hydroxide solution $(\mathrm{NaOH}, 50 \% \mathrm{w} / \mathrm{w})$ was purchased from Fisher Chemical (Fair Lawn, NJ). Sodium sulfide nonahydrate $\left(\mathrm{Na}_{2} \mathrm{~S} \cdot 9 \mathrm{H}_{2} \mathrm{O}\right.$, 98\%) was purchased from Beantown Chemical (Hudson, NH). Silicone oil was purchased from Sigma-Aldrich (St. Louis, MO). Acetaldehyde ( $\left.\mathrm{CH}_{3} \mathrm{CHO}, 99 \%\right)$ was purchased from Alfa Aesar (Ward Hill, MA). Deionized, distilled water with a resistance of $18.2 \mathrm{M} \Omega \times \mathrm{cm}$ at $25^{\circ} \mathrm{C}$ was provided by a Milli-Q system (Millipore Sigma; Burlington, MA) was used for all experiments. Nitrogen gas $\left(\mathrm{N}_{2}, \mathrm{UHP}\right)$ cylinders were supplied from Airgas USA LLC (Elmira, NY). Samples were held in a temperature-controlled incubator at $10^{\circ} \mathrm{C}$ until use.

Gas detection tubes (GDT). Commercially available gas detection tubes (Gastec International, San Diego, CA) used for analyses of $\mathrm{H}_{2} \mathrm{~S}($ Gastec $4 \mathrm{LT})$ and $\mathrm{SO}_{2}(\mathrm{Gastec} 5 \mathrm{~L})$ were purchased from Airgas (Radnor, PA) and W. W. Grainger (Lake Forest, IL), respectively. The $\mathrm{H}_{2} \mathrm{~S}$ 4LT

246 tubes rely on the reaction of $\mathrm{H}_{2} \mathrm{~S}$ with an $\mathrm{HgCl}_{2}$, resulting in a color change from yellow to pink.

247 The $\mathrm{SO}_{2} 5 \mathrm{~L}$ tubes rely on the reaction of $\mathrm{SO}_{2}$ with $\mathrm{BaCl}_{2}$ to generate $\mathrm{HCl}$, resulting in the 248 appearance of a yellow color. In this method, $\mathrm{SO}_{2}$ GDTs are used only for filtering the gas 249 stream of any volatilized $\mathrm{SO}_{2}$, to prevent interferences in the $\mathrm{H}_{2} \mathrm{~S}$ tube. Gastec 5L GDT in this method are not appropriate for quantification of $\mathrm{SO}_{2}$. GDTs should be stored at cool temperature, 251 refrigerated at $10^{\circ} \mathrm{C}$ or below, or as indicated on the package. After opening, GDTs may be used 
Catalyst Papers in Press are peer-reviewed, accepted articles that have not yet been edited or formatted, but may be cited by DOI. The final version may contain substantive or nonsubstantive changes.

doi: 10.5344/catalyst.2021.21003

252

253

254

255

256

257

258

259

260

261

262

263

264

265

266

267

268

269

270

271

reliably for several sequential analyses within one day (data not shown) but should be replaced with a new tube each day.

\section{Quantitation of free $\mathrm{H}_{2} \mathrm{~S}$ in wines using GDT with $\mathrm{N}_{2}$ sparging ( $\mathrm{N}_{2}$ Method). The $\mathrm{N}_{2}$}

Method is depicted in Figure 1(a). For an analysis, a volume of wine sample (up to $60 \mathrm{~mL}$ ) is added to a $100 \mathrm{~mL}$ round-bottom flask (A). For red wines, 4-5 drops of silicone oil were added to decrease foaming. One neck of the flask was fitted with a fritted impinger (B) from an AerationOxidation unit (Adams \& Chittenden Scientific Glass Coop, Berkeley, CA) and the impinger connected to an $\mathrm{N}_{2}$ cylinder on the inlet side (C). The outlet side was connected by PVC tubing to an $\mathrm{SO}_{2}$ scrubber (see next sub-section), e,g. an $\mathrm{SO}_{2}$ GDT (D), followed by an $\mathrm{H}_{2} \mathrm{~S}$ GDT (E). The sample was sparged with $\mathrm{N}_{2}$ for $10 \mathrm{~min}$ at ambient temperature $\left(\sim 20^{\circ} \mathrm{C}\right)$, and the length of color change on the $4 \mathrm{LT}$ tube measured. The flow rate was $\sim 100 \mathrm{~mL} / \mathrm{min}$, as faster flow rates would occasionally dislodge the GDT. Under these conditions, negligible change to the GDT stain length was observed after 10 min.

\section{Quantitation of free $\mathrm{H}_{2} \mathrm{~S}$ in wines using GDT with vacuum aspiration (Aspiration Method).}

In the Aspiration Method [Fig 1(b)], wine samples are added to a $100 \mathrm{~mL}$ pear shaped flask (A) and attached to a fritted impinger (B) left open to atmosphere. The outlet side was connected by PVC tubing to an $\mathrm{SO}_{2}$ scrubber (see next sub-section), e,g. a flask containing a $1.5 \%$ by volume acetaldehyde solution (C) and $\mathrm{SO}_{2}$ GDT (D), followed by an $\mathrm{H}_{2} \mathrm{~S}$ GDT (E). The outlet of the $\mathrm{H}_{2} \mathrm{~S}$ GDT is attached by PVC tubing to a vacuum source (F). The sample is vacuum aspirated for 10 min and analyses were carried out at room temperature $\left(\sim 20^{\circ} \mathrm{C}\right)$, and the length of color change 
Catalyst Papers in Press are peer-reviewed, accepted articles that have not yet been edited or formatted, but may be cited by DOI. The final version may contain substantive or nonsubstantive changes.

doi: $10.5344 /$ catalyst.2021.21003

272

273

274

275

276

277

278

279

280

281

282

283

284

285

286

287

288

289

290

291 on the 4LT tube measured. Unlike the $\mathrm{N}_{2}$ method, we encountered no issues with dislodging the tubes, as the highest gas flow rate we could achieve was $<100 \mathrm{~mL} / \mathrm{min}$.

Removal of $\mathrm{SO}_{2}$ interferences in $\mathbf{N}_{2}$ and Aspiration Methods. Three strategies were evaluated for preventing interferences of $\mathrm{SO}_{2}$ on the Gastec 4LL and 4LT tubes: i) inserting an $\mathrm{SO}_{2}$ GDT in series before the $\mathrm{H}_{2} \mathrm{~S}$ GDT, as shown in Fig 1(a), Item D or Fig 1(b), Item D; ii) pre-treating the sample with hydrogen peroxide or acetaldehyde; iii) inserting a $100-\mathrm{mL}$ pear-shaped flask containing $10 \mathrm{~mL}$ of $1.5 \%$ by volume acetaldehyde solution between the sample flask and the GDT, as shown in Fig 1(b), Item C. In evaluations, i) and iii) were carried out as described in the methods above. For pre-treatment of the samples in ii), an aliquot of the oxidizing agent was added directly to $60 \mathrm{~mL}$ of a commercial white wine which was previously observed to cause an interference in the 4LT GDT. $\mathrm{H}_{2} \mathrm{O}_{2}$ solution was prepared at $3.5 \%$ and added at 1,3 , and $6 \mathrm{~mL}$, corresponding to $0.06-0.35 \%$ by volume. Acetaldehyde was added at $5 \mu \mathrm{L}, 25 \mu \mathrm{L}, 50 \mu \mathrm{L}$ and $100 \mu \mathrm{L}$, corresponding to $0.01-0.17 \%$ by volume.

Effects of sample volume and analysis time. To evaluate the effects of sample volume on response, sample volume was varied from $6 \mathrm{~mL}$ to $66 \mathrm{~mL}$ while analyzing $\mathrm{H}_{2} \mathrm{~S}$ calibration standards (described below) by the $\mathrm{N}_{2}$ Method. A response factor (length of stain in mm per ng $\mathrm{H}_{2} \mathrm{~S}$ ) was then calculated for each condition. Analysis time was initially determined by recording the point when the color change ceased on the $\mathrm{H}_{2} \mathrm{~S}$ GDT for 6 and $10 \mathrm{~mL}$ samples of model wine or Milli-Q water spiked with $\mathrm{H}_{2} \mathrm{~S}$. Aliquots of $\mathrm{H}_{2} \mathrm{~S}$ standard solutions were added to the selected sample volume and the analysis of Free $\mathrm{H}_{2} \mathrm{~S}$ was carried out as previously described. When 
Catalyst Papers in Press are peer-reviewed, accepted articles that have not yet been edited or formatted, but may be cited by DOI. The final version may contain substantive or nonsubstantive changes.

doi: $10.5344 /$ catalyst.2021.21003

292

sample volumes were $\geq 60 \mathrm{~mL}$, the analysis time was increased to $10 \mathrm{~min}$ to reach the point where no additional color change was observed. Following optimization, analysis times of 10 min were used for all runs.

Method calibration. $\mathrm{Na}_{2} \mathrm{~S} \cdot 9 \mathrm{H}_{2} \mathrm{O}$ working solution $(50 \mu \mathrm{M})$ was freshly diluted from a standardized stock solution ( $5 \mathrm{mM})$ every $48 \mathrm{~h}$, and the stock solution was newly prepared every 2 weeks. Stock solutions were stored in the refrigerator when not in use. Calibration standards of $0.017,0.025,0.050,0.100$, and $0.150 \mu \mathrm{M}$ as $\mathrm{H}_{2} \mathrm{~S}$ were prepared in model wine $(12 \% \mathrm{ABV}, 5 \mathrm{~g} / \mathrm{L}$ tartaric acid, $\mathrm{pH}$ adjusted to 3.5 by dropwise addition of $\mathrm{NaOH}$ ). Calibration curves were prepared by plotting "length of stain (mm)" vs. "mass $\mathrm{H}_{2} \mathrm{~S}(\mathrm{ng})$ ".

The observed slopes from each approach were compared against the slopes indicated by the manufacturer's markings on the GDT tubes. Because the GDT markings are reported in units of ppm (v/v), the values were converted to units of "ng $\mathrm{H}_{2} \mathrm{~S}$ " using the Ideal Gas Law and the manufacturer's suggested $100 \mathrm{~mL}$ gas volume for air sampling ${ }^{18}$. Details of the conversion calculation are provided in the Supplementary Information.

Reproducibility. In-lab reproducibility was assessed for the $\mathrm{N}_{2}$ Method where an addition of $\mathrm{Na}_{2} \mathrm{~S} \cdot 9 \mathrm{H}_{2} \mathrm{O}$ working solution $(50 \mu \mathrm{M})$ was measured in Milli-Q water at two concentrations, $1.55 \mu \mathrm{g} / \mathrm{L}(\mathrm{n}=9)$ and $3.10 \mu \mathrm{g} / \mathrm{L}(\mathrm{n}=7)$, over the course of 4 weeks.

Figures of merit. Calibration curves were used to determine the linear range. The limit of detection (LOD) was calculated as $3.3 \times$ standard deviation for the lowest concentration standard $(0.6 \mu \mathrm{g} / \mathrm{L}$ or $34 \mathrm{ng}$ using $60 \mathrm{~mL}$ sample volume $)$ within the linear range $(0-5.1 \mu \mathrm{g} / \mathrm{L}$, or $0-307$ 
Catalyst Papers in Press are peer-reviewed, accepted articles that have not yet been edited or formatted, but may be cited by DOI. The final version may contain substantive or nonsubstantive changes.

doi: $10.5344 /$ catalyst.2021.21003

312

313

314

315

316

317

318

319

320

321

322

323

324

325

326

327

328

329

330

331

332

333

334

335

336

337

338

ng using $60 \mathrm{~mL}$ sample volume). Standard deviations were determined for each calibration

standards, and the coefficient of variance was calculated as the mean of these values.

Evaluation of commercial wines. A convenient sample of commercial bottled ( $n=6,2$ red, 4

white) and canned ( $\mathrm{n}=6,2$ white, 2 rosé, 2 rosé sparkling) wines was purchased from local

retailers (Ithaca, NY) and represented a range of regions and cultivars. Vintages ranged from 1-3

years old, although a few products were labeled as "non-vintage". Bottled samples were

analyzed for $\mathrm{H}_{2} \mathrm{~S}$ in duplicate and canned samples were analyzed in triplicate.

Statistical Analysis. JMP Pro 14 (SAS Institute Inc., Cary, NC) was used for statistical analysis.

\section{References and Endnotes}

1. Siebert, T. E.; Solomon, M. R.; Pollnitz, A. P.; Jeffery, D. W., 2010, Selective determination of volatile sulfur compounds in wine by gas chromatography with sulfur chemiluminescence detection. $J$ Agric Food Chem 58:9454-62.

2. Giudici, P.; Kunkee, R. E., 1994, The Effect of Nitrogen Deficiency and Sulfur-Containing Amino Acids on the Reduction of Sulfate to Hydrogen Sulfide by Wine Yeasts. American Journal of Enology and Viticulture 45:107-112.

3. Kwasniewski, M. T.; Allison, R. B.; Wilcox, W. F.; Sacks, G. L., 2011, Convenient, inexpensive quantification of elemental sulfur by simultaneous in situ reduction and colorimetric detection. Analytica Chimica Acta 703:52-7.

4. Jastrzembski, J. A.; Allison, R. B.; Friedberg, E.; Sacks, G. L., 2017, Role of Elemental Sulfur in Forming Latent Precursors of H2S in Wine. J Agric Food Chem 65:10542-10549.

5. Pripis-Nicolau, L.; de Revel, G.; Bertrand, A.; Maujean, A., 2000, Formation of Flavor Components by the Reaction of Amino Acid and Carbonyl Compounds in Mild Conditions. J Agric Food Chem 48:3761-3766.

6. Park, S. K.; Boulton, R. B.; Noble, A. C., 2000, Formation of Hydrogen Sulfide and Glutathione During Fermentation of White Grape Musts. American Journal of Enology and Viticulture 51:91-97.

7. Bekker, M. Z.; Kreitman, G. Y.; Jeffery, D. W.; Danilewicz, J. C., 2018, Liberation of Hydrogen Sulfide from Dicysteinyl Polysulfanes in Model Wine. J Agric Food Chem 66:13483-13491. 
Catalyst Papers in Press are peer-reviewed, accepted articles that have not yet been edited or formatted, but may be cited by DOI. The final version may contain substantive or nonsubstantive changes.

doi: $10.5344 /$ catalyst.2021.21003

8. Kreitman, G. Y.; Danilewicz, J. C.; Jeffery, D. W.; Elias, R. J., 2017, Copper(II)-Mediated Hydrogen Sulfide and Thiol Oxidation to Disulfides and Organic Polysulfanes and Their Reductive Cleavage in Wine: Mechanistic Elucidation and Potential Applications. J Agric Food Chem 65:25642571.

9. Franco-Luesma, E.; Ferreira, V., 2014, Quantitative analysis of free and bonded forms of volatile sulfur compouds in wine. Basic methodologies and evidences showing the existence of reversible cationcomplexed forms. J Chromatogr A 1359:8-15.

10. Ugliano, M.; Kwiatkowski, M.; Vidal, S.; Capone, D.; Siebert, T.; Dieval, J. B.; Aagaard, O.; Waters, E. J., 2011, Evolution of 3-mercaptohexanol, hydrogen sulfide, and methyl mercaptan during bottle storage of Sauvignon blanc wines. Effect of glutathione, copper, oxygen exposure, and closurederived oxygen. J Agric Food Chem 59:2564-72.

11. Ugliano, M.; Kolouchova, R.; Henschke, P. A., 2011, Occurrence of hydrogen sulfide in wine and in fermentation: influence of yeast strain and supplementation of yeast available nitrogen. Journal of Industrial Microbiology \& Biotechnology 38:423-429.

12. Acree, T. E.; Sonoff, E. P.; Splittstoesser, D. F., 1972, Effect of Yeast Strain and Type of Sulfur Compound on Hydrogen Sulfide Production. American Journal of Enology and Viticulture 23:6-9.

13. Lopez, R.; Lapena, A. C.; Cacho, J.; Ferreira, V., 2007, Quantitative determination of wine highly volatile sulfur compounds by using automated headspace solid-phase microextraction and gas chromatography-pulsed flame photometric detection. Critical study and optimization of a new procedure. J Chromatogr A 1143:8-15.

14. Ugliano, M.; Henschke, P., 2010, Comparison of three methods for accurate quantification of hydrogen sulfide during fermentation. Analytica Chimica Acta 660:87 - 91.

15. Park, S.-K., 2008, Development of a method to measure hydrogen sulfide in wine fermentation. J Microbiol Biotechnol 18:1550-1554.

16. Kreitman, G. Y.; Elias, R. J.; Jeffery, D. W.; Sacks, G. L., 2019, Loss and formation of malodorous volatile sulfhydryl compounds during wine storage. Crit Rev Food Sci Nutr 59:1728-1752.

17. Chen, Y.; Jastrzembski, J. A.; Sacks, G. L., 2017, Copper-Complexed Hydrogen Sulfide in Wine: Measurement by Gas Detection Tubes and Comparison of Release Approaches. American Journal of Enology and Viticulture 68:91-99.

18. Gastec, Instructions for Hydrogen Sulphide Detector Tube. In Gastec No. 4LT, Gastec Corporation: Kanagawa, Japan.

19. Fang, Y.; Qian, M. C., 2005, Sensitive quantification of sulfur compounds in wine by headspace solid-phase microextraction technique. J Chromatogr A 1080:177-85.

20. Allison, R. B.; Sacks, G. L.; Montgomery, A.; Bandić, L. M.; Goddard, J., 2020, The Chemistry of Canned Wine; Appellation Cornell 40. 
Table 1 Figures of merit for $\mathrm{H}_{2} \mathrm{~S}$ GDT $\mathrm{N}_{2}$ and Aspiration Methods.

\begin{tabular}{|l|c|c|c|c|c|}
\hline & Mean \%CV & $\begin{array}{c}\text { Linear range } \\
\left(\mathrm{ng} \mathrm{H} \mathrm{H}_{2} \mathrm{~S}\right)\end{array}$ & $\mathrm{r}^{2}$ & $\begin{array}{c}\mathrm{LOD}^{\mathrm{b}} \\
\left(\mathrm{ng} \mathrm{H} \mathrm{H}_{2} \mathrm{~S}\right)\end{array}$ & $\begin{array}{c}\mathrm{LOD}^{\mathrm{b}} \\
\left(\mu \mathrm{gg} / \mathrm{L} \mathrm{H}_{2} \mathrm{~S} \text { for }\right. \\
60 \mathrm{~mL} \text { sample })\end{array}$ \\
\hline $\mathrm{N}_{2}$ Method & 4.5 & $0-307$ & 0.9991 & 13 & 0.2 \\
\hline $\begin{array}{l}\text { Aspiration } \\
\text { Method }\end{array}$ & 4.1 & $0-875$ & 0.9993 & 12 & 0.2 \\
\hline
\end{tabular}

(a) Mean and range for $\%$ coefficient of variation $(\mathrm{CV})$, where $\% \mathrm{CV}$ for each wine was calculated as (standard deviation / mean).

(b) Limit of detection (LOD) is calculated as $3.3 \times$ standard deviation of the lowest concentration standard divided by the slope. 
Catalyst Papers in Press are peer-reviewed, accepted articles that have not yet been edited or formatted, but may be cited by DOI. The final version may contain substantive or nonsubstantive changes.

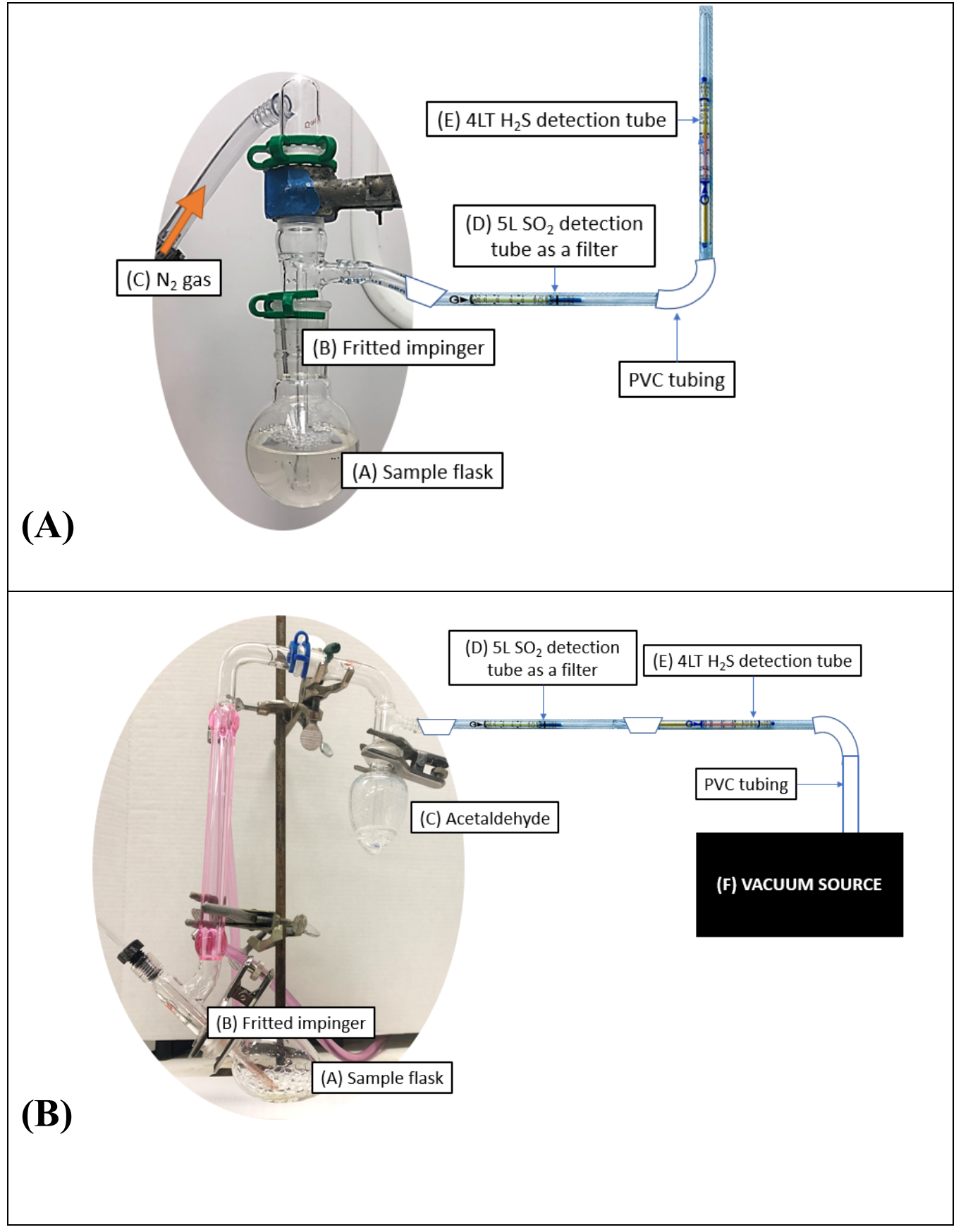

Figure 1 Apparatus for measuring $\mathrm{H}_{2} \mathrm{~S}$ using (A) inert gas $\left(\mathrm{N}_{2}\right)$ sparging and (B) vacuum aspiration. The sample flask is connected to an impinger and the gas detection tubes (GDTs) are connected to the outlet, in series. 
Catalyst Papers in Press are peer-reviewed, accepted articles that have not yet been edited or formatted, but may be cited by DOI. The final version may contain substantive or nonsubstantive changes.

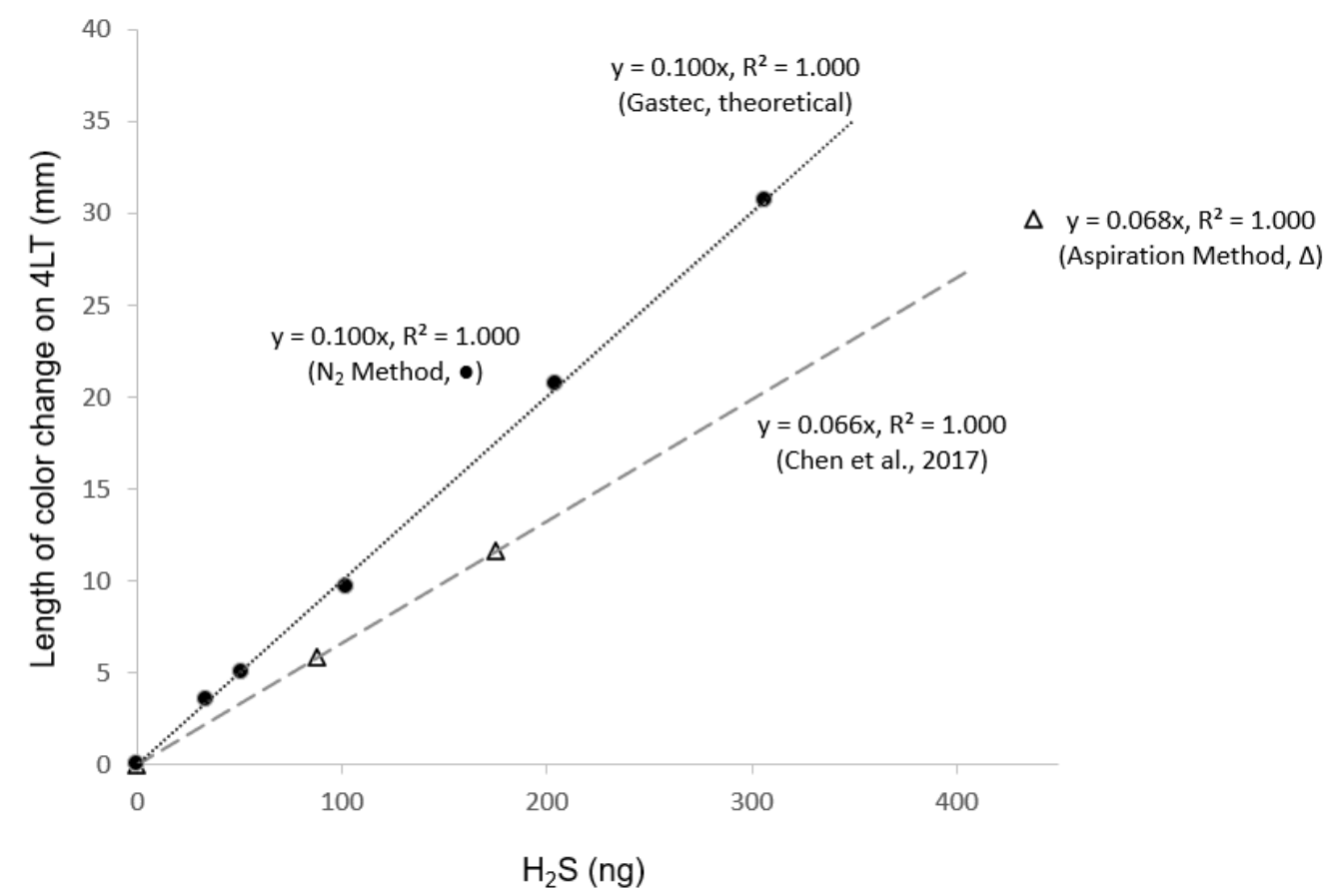

Figure 2 Calibration curves for $\mathrm{H}_{2} \mathrm{~S}$ [mass of $\mathrm{H}_{2} \mathrm{~S}$ (y, ng) vs. stain length (x, mm)] on Gastec 4LT gas detection tubes: (i) Aspiration Method from the current study, regression equation is $y=14.7 \mathrm{x}$, (ii) $\mathrm{N}_{2}$ Method from the current study, $y=10.0 x$, (iii) Alka-Seltzer tablet sparging, with regression equation calculated from reported values (Chen et al, 2017), $y=14.9 x$. The Manufacturer's theoretical regression equation $\left(\mathrm{H}_{2} \mathrm{~S}\right.$ vs. stain length) calculated from tube markings, $\mathrm{y}=10.0 \mathrm{x}$, labeled as (iv). For all regressions, the intercept was not significantly different from zero and was omitted. 
Catalyst Papers in Press are peer-reviewed, accepted articles that have not yet been edited or formatted, but may be cited by DOI. The final version may contain substantive or nonsubstantive changes.

doi: $10.5344 /$ catalyst.2021.21003

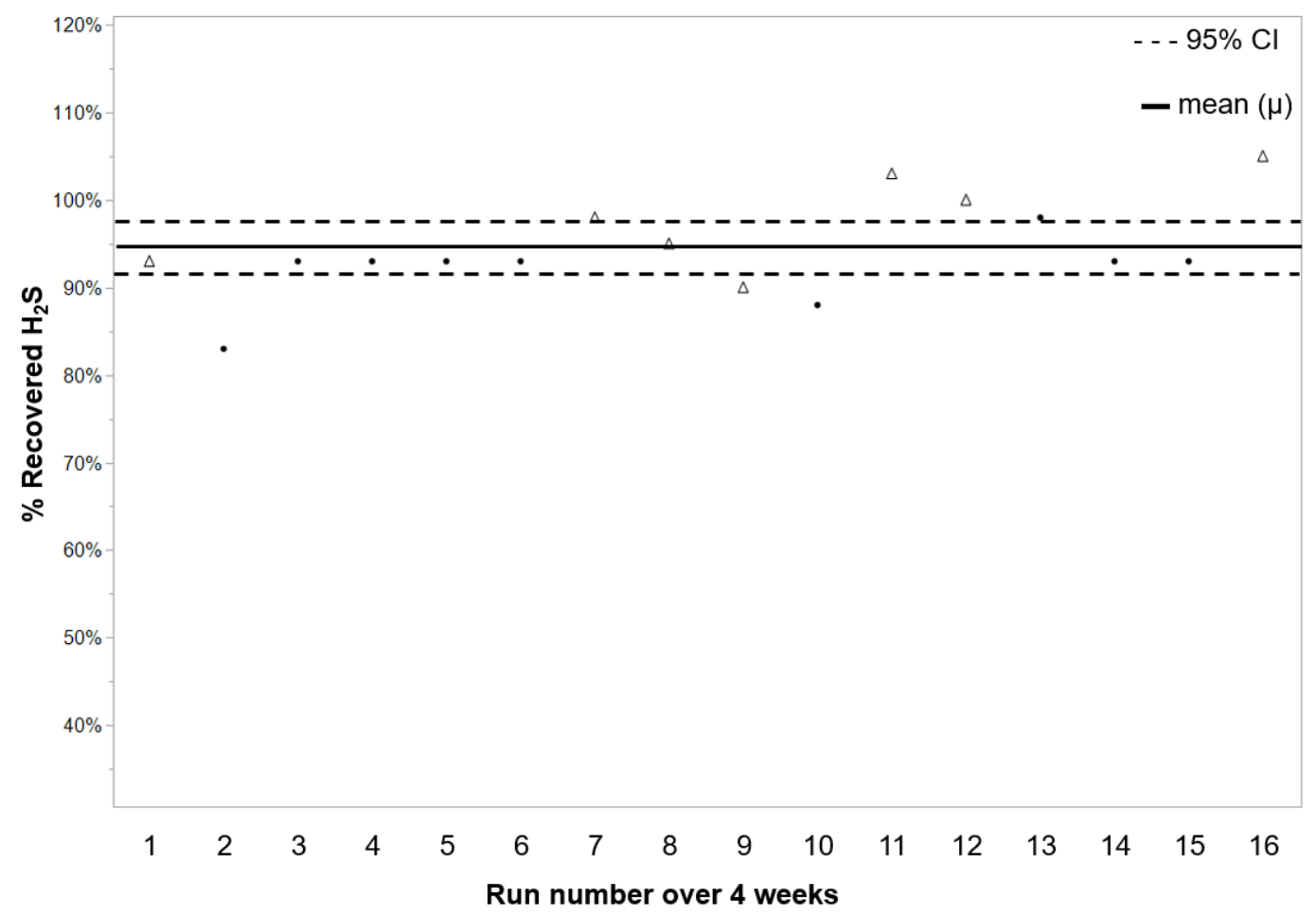

Figure 3 In-lab reproducibility of $\mathrm{N}_{2}$ Method measured over 4 weeks with higher concentration $(\Delta)=$ $3.10 \mu \mathrm{g} / \mathrm{L}(\mathrm{n}=7)$ or lower concentration $(\bullet)=1.55 \mu \mathrm{g} / \mathrm{L} \mathrm{ng}(\mathrm{n}=9)$ standards. Sample measurements are normalized to the expected value (\% Recovery $\mathrm{H}_{2} \mathrm{~S}=\mathrm{H}_{2} \mathrm{~S}$ measured $/ \mathrm{H}_{2} \mathrm{~S}$ added $)$. The $95 \% \mathrm{CI}$ is shown as $\mu=94.4 \pm 2.9 \%$. 
Catalyst Papers in Press are peer-reviewed, accepted articles that have not yet been edited or formatted, but may be cited by DOI. The final version may contain substantive or nonsubstantive changes.

doi: $10.5344 /$ catalyst.2021.21003

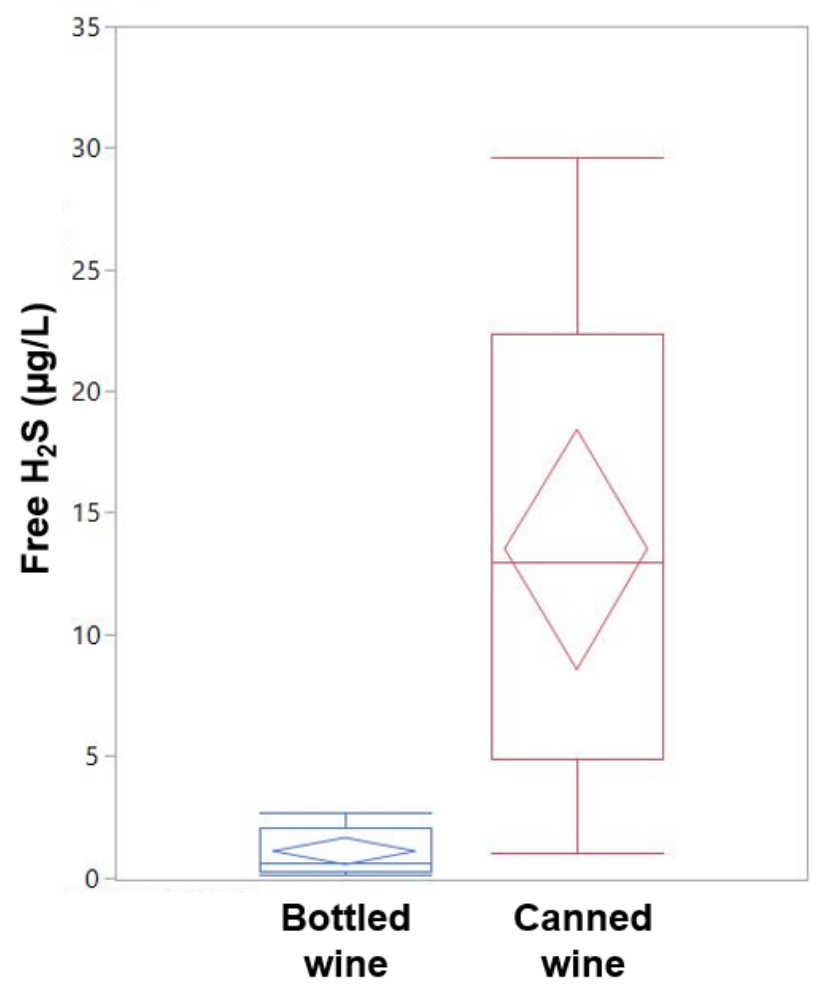

Figure 4 Quantitation of free $\mathrm{H}_{2} \mathrm{~S}$ in a selection of commercial bottled $(\mathrm{n}=6)$ and canned wines $(\mathrm{n}=6)$. 
Catalyst Papers in Press are peer-reviewed, accepted articles that have not yet been edited or formatted, but may be cited by DOI. The final version may contain substantive or nonsubstantive changes.

Supplemental Figure A Color change in Gastec 4LT (a, b), 4LL (c, d) and 5L (e, f) gas detection tubes, showing tubes before $(b, d, f)$ and after $(a, c, e)$ use.
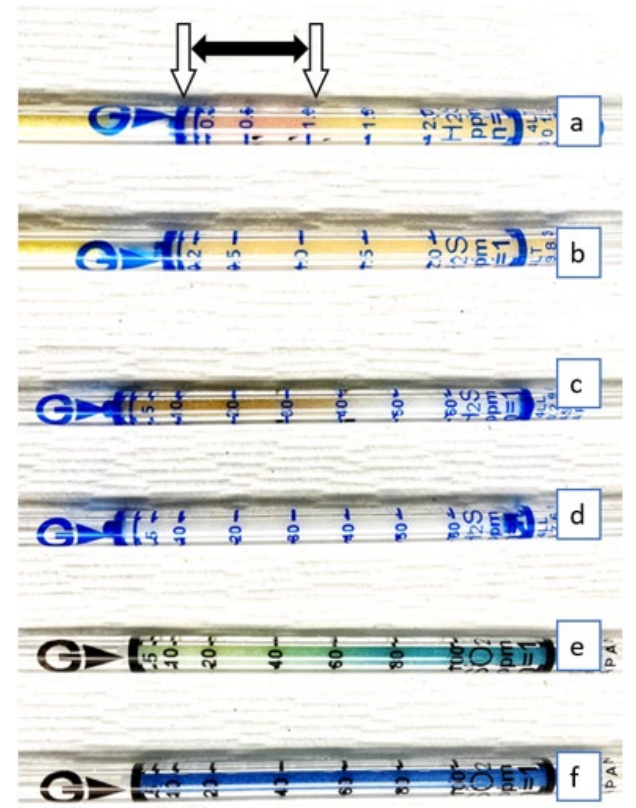

\section{Supplemental Figure B - GDT sensitivity as a function of sample volume}

The response of the GDT method ( $\mathrm{mm}$ stain per ng $\mathrm{H}_{2} \mathrm{~S}$ ) with changing sample volume. Measurements were performed by the $\mathrm{N}_{2}$ Method, and samples are prepared in both model wine and water. The response did not differ significantly (ANOVA, $\mathrm{p}>0.05$ ) as a function of sample volume.

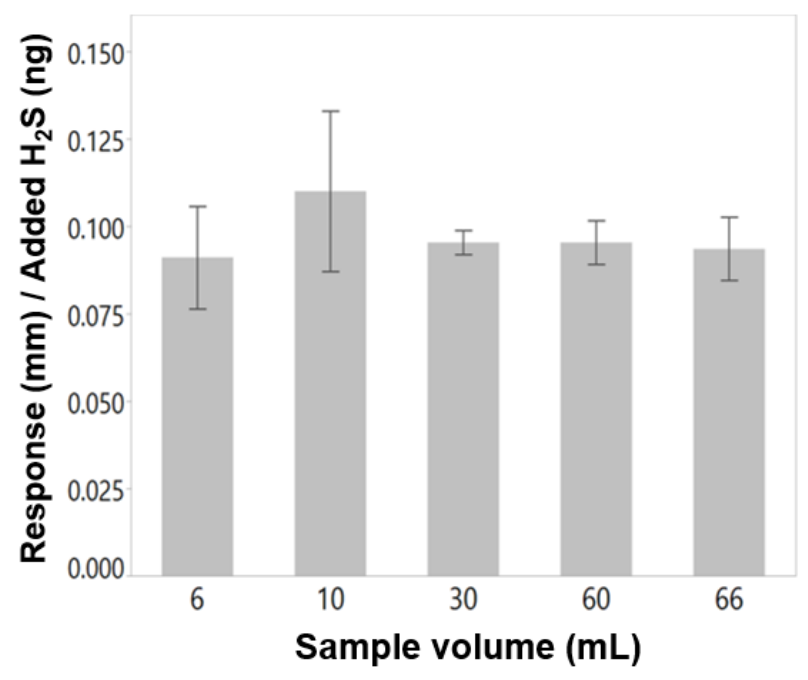


Catalyst Papers in Press are peer-reviewed, accepted articles that have not yet been edited or formatted, but may be cited by DOI. The final version may contain substantive or nonsubstantive changes.

\section{Supplemental Calculation - Theoretical mass of $\mathrm{H}_{2} \mathrm{~S}$ determined from 4LT GDT concentration markings (length of color change in $\mathrm{mm}$ to $\mathrm{ng}$ ):}

\begin{tabular}{|c|c|c|c|}
\hline $\begin{array}{c}\text { 4LT mm } \\
\text { markings }\end{array}$ & $\begin{array}{c}\text { 4LT } \\
\text { concentration } \\
\text { markings } \\
\text { ("ppm") }\end{array}$ & $\begin{array}{c}\text { 4LT markings } \\
\text { (mol equivalent) }\end{array}$ & 4LT ng \\
\hline 7 & 0.5 & $2.1 \mathrm{E}-09$ & 69.9 \\
\hline 14 & 1.0 & $4.1 \mathrm{E}-09$ & 139.9 \\
\hline 21 & 1.5 & $6.2 \mathrm{E}-09$ & 209.8 \\
\hline 28 & 2.0 & $8.2 \mathrm{E}-09$ & 279.8 \\
\hline 35 & - & $1.0 \mathrm{E}-08$ & 349.7 \\
\hline
\end{tabular}

Conversion from "ppm" to "ng" for the manufacturer calibrated quantity of gas on the 4LT GDT, using Ideal Gas Law, $P V=n R T$.

\begin{tabular}{|r|l|l|}
\hline Volume, $\mathrm{V}=$ & 0.1 & $\mathrm{~L}$ \\
\hline Pressure, $\mathrm{P}=$ & 1 & bar \\
\hline Ideal gas constant, $\mathrm{R}=$ & 0.083144598 & $\mathrm{~L}$ bar/mol K \\
\hline Temperature, $\mathrm{T}=$ & 293 & $\mathrm{~K}$ \\
\hline Moles in 0.1 L of gas, $\mathrm{n}=$ & 0.004105 & $\mathrm{~mol}$ \\
\hline
\end{tabular}

Definition of "ppm" = moles of $\mathrm{H}_{2} \mathrm{~S} / 1,000,000$ moles of gas

\begin{tabular}{|l|l|l|}
\hline (a) & $1 \mathrm{ppm}=$ & $1 \mathrm{~mol} \mathrm{H}_{2} \mathrm{~S} / 1,000,000$ moles gas \\
\hline (b) & $1 \mathrm{ppm}=$ & $4.10 \mathrm{E}-09 \mathrm{~mol} \mathrm{H}_{2} \mathrm{~S} / 0.004105 \mathrm{~mol}$ gas \\
\hline (c) & $1 \mathrm{ppm}=$ & $139.9 \mathrm{ng} \mathrm{H}_{2} \mathrm{~S}$ \\
\hline
\end{tabular}

The concentration markings in ppm on the GDT were reported with their corresponding length of color change in $\mathrm{mm}$. Then, the ppm markings are converted to what it would be in moles and mass of $\mathrm{H}_{2} \mathrm{~S}$, because the tubes are calibrated to measure concentration in $100 \mathrm{~mL}$ gas samples. Moles of gas that correspond to a $100 \mathrm{~mL}$ gas sample is calculated assuming Ideal Gas Law under the indicated conditions.

A sample containing $1 \mathrm{~mol}$ of $\mathrm{H}_{2} \mathrm{~S}$ in 1,000,000 mol of gas should correspond to the " $1 \mathrm{ppm}$ " mark on the GDT (a). Therefore, a $100 \mathrm{~mL}$ sample containing $0.004105 \mathrm{~mol}$ of gas and producing " $1 \mathrm{ppm}$ " on the GDT would contain $0.004105 / 1,000,000=4.10 \mathrm{E}-0.9$ mol of $\mathrm{H}_{2} \mathrm{~S}(\mathrm{~b})$.

Finally, moles of $\mathrm{H}_{2} \mathrm{~S}$ required to get a "1 ppm" mark on the GDT is converted to mass, using the molecular weight of $\mathrm{H}_{2} \mathrm{~S}(34.076 \mathrm{~g} / \mathrm{mol})$, meaning that is the total mass $\mathrm{H}_{2} \mathrm{~S}$ that has been measured on the tube up to that mark (c). Using the amount of $\mathrm{H}_{2} \mathrm{~S}$ calculated for " $1 \mathrm{ppm}$ ", the value is scaled to get the mass of $\mathrm{H}_{2} \mathrm{~S}$ for all ppm markings and their corresponding mm measurements, giving the theoretical relationship $\mathrm{H}_{2} \mathrm{~S}$ (ng) $=\mathbf{1 0 . 0} \times \mathbf{m m}$ on $4 \mathrm{LT}$. 
Catalyst Papers in Press are peer-reviewed, accepted articles that have not yet been edited or formatted, but may be cited by DOI. The final version may contain substantive or nonsubstantive changes.

doi: 10.5344/catalyst.2021.21003

Supplemental Video 1 - Analysis of Free Hydrogen Sulfide in Wines Using Gas Detection Tubes 